\title{
ESTUDO COMPARATIVO ENTRE OS MÉTODOS DE COMPACTAÇÃO DE SOLOS POR IMPACTO E AMASSAMENTO
}

\author{
COMPARATIVE STUDY BETWEEN SOIL COMPACTION BY IMPACT AND GRINDING \\ METHODS
}

\section{Danielle Savala Vieira SOBREIRA, Adriano Elísio de Figueiredo Lopes LUCENA, Lêda Christiane de Figueirêdo Lopes LUCENA, Talita Miranda de SOUSA}

Universidade Federal de Campina Grande, Unidade Acadêmica de Engenharia Civil. Campina Grande - PB. Email: lucenafb@uol.com.br; danielle_admeng@yahoo.com.br; ledach@uol.com.br; talita.miranda@hotmail.com

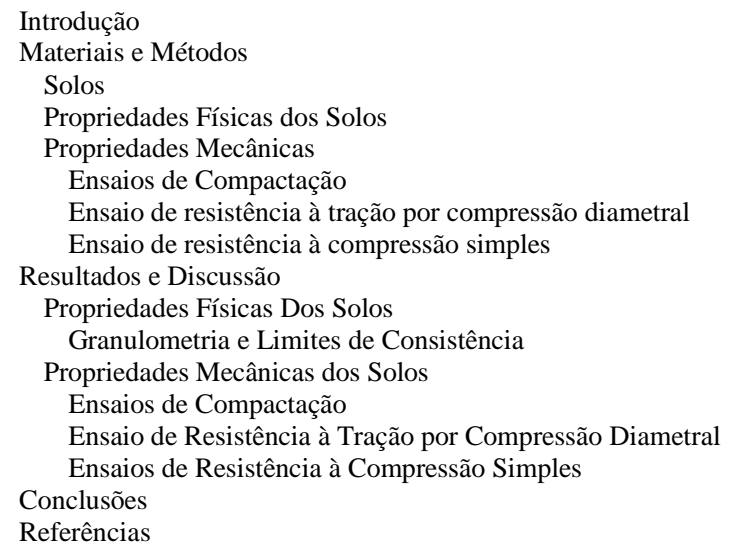

\begin{abstract}
RESUMO - A compactação Proctor por impacto representa o método de laboratório ainda mais empregado mundialmente para determinar a massa específica seca máxima e umidade ótima dos solos. Procedimentos de compactação de camadas de solo no campo se desenvolveram muito nos últimos anos no que diz respeito a técnicas e tecnologias, e em contrapartida, os ensaios de Proctor permaneceram inalterados. Por conseguinte, um método mais moderno de compactação de solos em laboratório é necessário devido os ensaios Proctor não simularem com precisão métodos de compactação de campo moderno, que dependem de uma combinação de amassamento, vibração e impacto. Uma alternativa que simula estes mecanismos de compactação em amostras no laboratório é com o uso do Compactador Giratório Superpave (CGS). Este trabalho propõe comparar o efeito da Compactação Proctor (por impacto) e da Compactação CGS (por amassamento) usando três energias (Normal, Intermediário e Modificado) em três tipos de solos (arenoso, siltoso e argiloso). Foram realizados ensaios tais como: compactação, resistência à tração por compressão diametral e resistência à compressão simples. De um modo geral, esta pesquisa mostrou que a compactação giratória no CGS é um método viável de compactação de solo em laboratório.
\end{abstract}

Palavras-chave: Compactação de solos; método Proctor; compactador giratório Superpave.

\begin{abstract}
The Proctor compaction by impact is the most used laboratory method in the world to determine the maximum dry density and optimum moisture content of soil. Procedures of compaction of soil layers in the field have been evolving in recent years with regard to techniques and technologies, and in turn, Proctor tests have remained unchanged. Therefore, a more modern method of compacting soil in laboratory is necessary because the Proctor tests do not accurately simulate compression methods of the modern field, which rely on a combination of kneading, vibration and impact. This work proposes to compare the effect of Proctor compaction (by impact) and SGC Compaction (by kneading) by using three energies (Standard, Intermediate and Modified) in three soil types (sandy, silty and clay), to assess the effects of these compression processes in the geotechnical behavior of these soils. Tests such as compaction, tensile strength by diametral compression, and unconfined compression were performed. Overall, this research showed that gyratory compression in SGC is a viable method of soil compaction in the laboratory; however, for SGC to be used routinely in the compaction of soils in the laboratory.
\end{abstract}

Keywords: Soil compaction; Proctor method; Superpave Gyratory Compactor.

\section{INTRODUÇÃO}

A compactação dos solos tem sido usada em várias obras de engenharia tais como, aterros, diques, estradas e barragens de terra, por engenheiros e construtores durante séculos como um método de construção destas estruturas. Na sua grande maioria, o solo que é o principal material de engenharia para estas construções, apresenta propriedades geotécnicas em condições não recomendadas ou desejáveis para sua execução. Desta forma é necessária a compactação do solo como forma de melhoramento destas propriedades.

Os benefícios ou melhorias das propriedades do solo que ocorrem como resultado da compactação de solo segundo Holtz \& Kovacs (1981) são: aumento da estabilidade, aumento da capacidade de suporte das camadas de subleitos de pavimentos; redução e/ou prevenção de adensamento do solo; e melhor controle de variações indesejadas de volume, 
como retração e expansão e redução da erodibilidade.

Para determinar e/ou quantificar as propriedades de solo necessárias para a compactação de campo é necessária a comparação entre a compactação de campo à compactação do solo de laboratório (Browne, 2006).

O ensaio de compactação de laboratório mais difundido foi apresentado em 1933 pelo engenheiro americano chamado Ralph R. Proctor, o qual estabeleceu que a compactação é uma função do peso específico do solo, teor de umidade, energia de compactação e do tipo de solo. No ensaio Proctor, a amostra de solo é submetida a um processo de compactação dinâmica ou por impacto, no qual a amostra de solo é confinada em um molde e submetida a uma série de golpes por um soquete. $\mathrm{Na}$ compactação do solo de campo o procedimento consiste em espalhar o material uniformemente, em camadas, e a compactação é feita empregando amassamento e vibração.

Os equipamentos de compactação de campo, assim como as técnicas e a tecnologia empregadas, desenvolveram-se muito nos últimos anos e, em contrapartida, o principal método de compactação de laboratório, o ensaio Proctor, não evoluiu muito desde a sua concepção. Desta forma, pesquisas sobre métodos de compactação de solos em laboratório vêm sendo retomadas com o intuito de buscar um mecanismo de ação que simule de forma mais semelhante a compactação de campo, se comparado ao ensaio Proctor, e para isso o uso dos compactadores giratórios tem sido uma solução.

Segundo Marques (2004) o desenvolvimento do conceito da compactação giratória é atribuído aos engenheiros do Departamento de Rodovias do Texas, na década de 1930. É baseado em especificações estabelecidas para os agregados e nas proporções volumétricas da mistura asfáltica. Por sua vez, as misturas são "projetadas" com o auxílio de parâmetros relacionados com as propriedades físicas, químicas e mecânicas dos agregados, bem como pela relação volume de vazios, volume de CAP (Cimento Asfáltico de Petróleo) e volume de agregado.

Os compactadores giratórios são equipamentos capazes de aplicar simultaneamente uma carga vertical e uma tensão cisalhante, por meio do giro do molde de compactação sob um ângulo de inclinação (Ping et al., 2003). Atualmente, mais de 2.000 compactadores giratórios Superpave (CGS) estão em uso nos Estados Unidos para a gestão de projeto de campo de misturas asfálticas. Na sua maioria esses modelos fornecem um meio de ajustar e calibrar os quatro parâmetros primários que afetam o grau de compactação de amostras de laboratório: i) ângulo de inclinação, ii) pressão confinante, iii) a taxa de rotação e iv) número de giros (Mzokwa et al., 2008).

Diante do exposto, esta pesquisa tem por objetivo comparar o processo de compactação do solo de laboratório (Proctor) com um método de compactação novo que utiliza o compactador giratório Superpave (CGS) para compactar amostras de solo.

\section{MATERIAIS E MÉTODOS}

A metodologia foi seguida conforme o Solos fluxograma mostrado na figura 1 .

O programa experimental dessa pesquisa foi dividido em etapas. A primeira etapa da pesquisa teve o intuito de obter, preparar e classificar os solos (arenoso, siltoso e argiloso). Esta fase é importante para a realização da caracterização mecânica, em que os ensaios serão citados posteriormente.

Os métodos de ensaios utilizados foram baseados em normas da Associação Brasileira de Normas Técnicas (ABNT), do Departamento Nacional de Infraestrutura de Transportes (DNIT) e da American Association of State Highway and Transportation Officials (AASHTO).
Para realização desta pesquisa foram escolhidos três tipos de solos: arenoso, siltoso e argiloso (Figura 2). Os solos arenoso e siltoso foram provenientes da Jazida 01 da obra Barragem Cupissura, nas cidades de Pitimbu e Caaporã, no estado da Paraíba. As amostras dos solos foram coletadas a diferentes profundidades. O solo arenoso foi obtido em profundidades entre $0,10 \mathrm{~m}$ e $1,10 \mathrm{~m}$, e para o solo siltoso as profundidades variaram de 0,20m a 3,30m. O solo argiloso foi coletado em um talude na BR232 (Km 14), entrada para Jaboatão Velho, na cidade de Recife, no estado de Pernambuco. As amostras de solo foram coletadas na margem direita, sob as coordenadas (80 5’ 45” Latitude) e (350 1' 71” Longitude). 


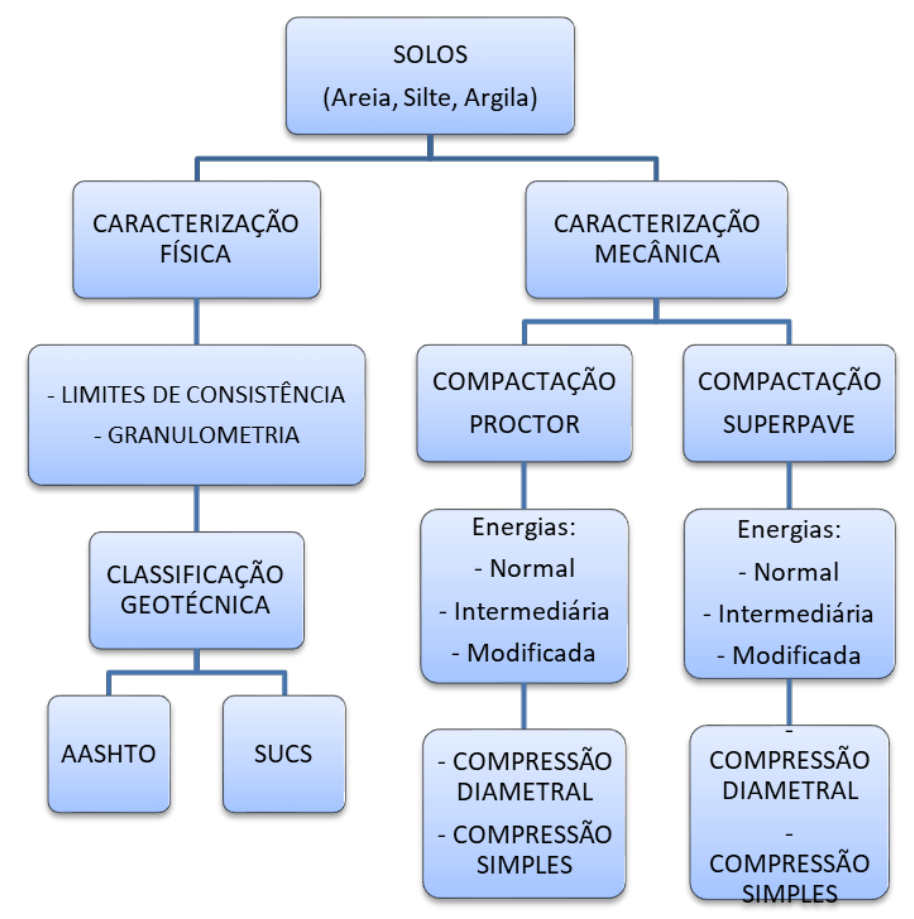

Figura 1 - Sequência de atividades realizadas.
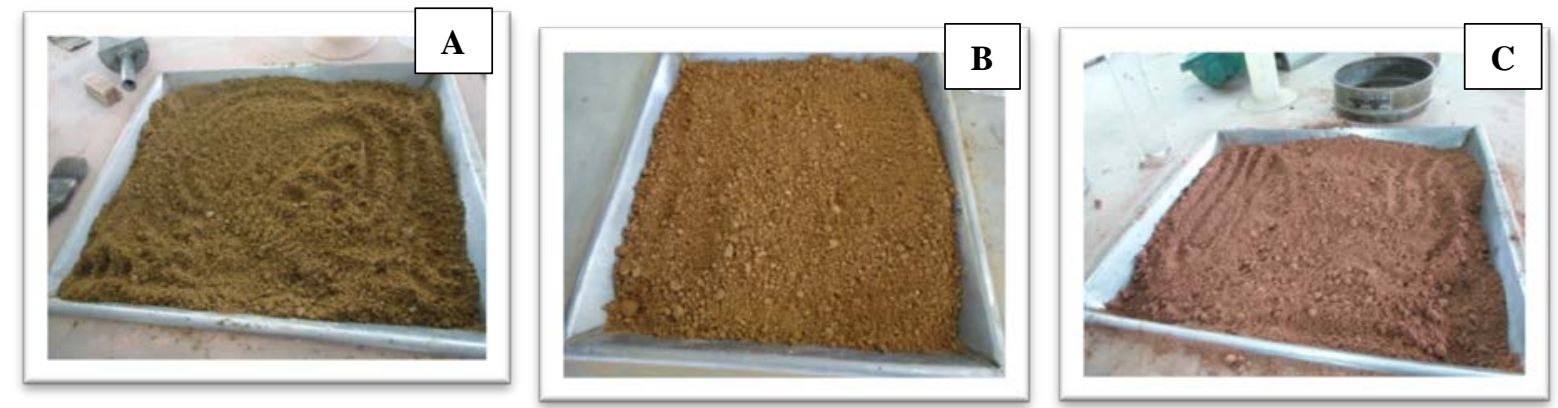

Figura 2 - Amostra do solo (a) arenoso (b) siltoso e (c) argiloso.

\section{Propriedades Físicas dos Solos}

Todos os ensaios de caracterização física foram realizados no Laboratório de Engenharia de Pavimentos (LEP) do Departamento de Engenharia Civil da Universidade Federal de Campina Grande (UFCG). Nesta etapa, a preparação das amostras de solo foi realizada de acordo a NBR 6457 (ABNT, 1986) - Amostras de solo - Preparação para ensaios de compactação e ensaios de caracterização. Na tabela 1 estão inseridas as normas adotadas para cada ensaio de caracterização física das amostras dos solos.

Tabela 1 - Normas adotadas para caracterização física das amostras dos solos.

\begin{tabular}{l|l}
\hline \multicolumn{1}{c|}{ Ensaio } & Método \\
\hline Análise granulométrica - Solo & ABNT- NBR 7181/2016 \\
\hline Determinação do limite de liquidez & ABNT- NBR 6459/2016 \\
\hline Determinação do limite de plasticidade & ABNT- NBR 7180/2016 \\
\hline
\end{tabular}

\section{Propriedades Mecânicas}

Os ensaios realizados para a caracterização mecânica dos solos foram: compactação, resistência à tração por compressão diametral e resistência à compressão simples. Na tabela 2 estão inseridas as normas adotadas para cada ensaio de caracterização mecânica das amostras dos solos.

\section{Ensaios de Compactação}

Para se alcançar o objetivo principal desta pesquisa foram realizados dois tipos de ensaios de compactação, um manual de acordo com a metodologia Proctor e a outra mecânica com o uso do compactador giratório. Os ensaios de compactação Proctor foram executados nas energias Normal, Intermediária e Modificada, 
com reuso de material e compactação manual. A escolha por realizar a compactação com reuso foi baseada em dois fatores: quantidade de amostra disponível e a não ocorrência de alteração na granulometria dos solos estudados após a compactação. Para os ensaios de compactação no CGS como não existem normas que o regulamentem fez-se uso dos estudos existentes sobre este tema (Browne, 2006; Ping et al., 2003; Dantas, 2013).

Tabela 2 - Normas adotadas para caracterização mecânica das amostras dos solos.

\begin{tabular}{l|c}
\hline \multicolumn{1}{c|}{ Ensaio } & Método \\
\hline Ensaio de compactação - Solo & DNIT - ME 162/1994 \\
\hline Determinação da resistência à tração por compressão diametral & DNIT - ME 136/2010 \\
\hline Ensaio de compressão simples de corpos de prova cilíndricos - Solo - cimento & ABNT- NBR 12025/2012 \\
\hline
\end{tabular}

O ensaio de compactação Proctor consiste na compactação de camadas de uma amostra de solo confinado em um molde, na qual se aplicam golpes com um soquete. Conforme a energia de compactação é definida, variam-se o número de camadas, o peso do soquete e o volume do molde (Tabela 3). A tabela 4 apresenta as energias empregadas nos ensaios Proctor por unidade de volume e por unidade de massa.

A compactação de um solo em laboratório tem a finalidade de determinar a curva de variação da densidade do solo em função da umidade, para uma dada energia de compactação. Para a metodologia Proctor as curvas de compactação apresentam os parâmetros ótimos, teor de umidade (w) e massa especifica aparente seca (MEAS).

Na compactação utilizando o compactador giratório o procedimento é realizado pela aplicação, de maneira simultânea, de uma tensão normal que advém de um pistão, e de uma força de cisalhamento decorrente do giro do molde cilíndrico em torno do seu próprio eixo sob um determinado ângulo de inclinação do próprio molde. Os moldes cilíndricos utilizados nesta pesquisa são os moldes com $100 \mathrm{~mm}$ de diâmetro e $270 \mathrm{~mm}$ de altura, para os ensaios de compactação, compressão diametral e compressão simples.

Tabela 3 - Parâmetros de compactação do ensaio Proctor.

\begin{tabular}{l|c|c|c|c}
\hline Energia & $\begin{array}{c}\text { Massa do soquete } \\
(\mathbf{k g})\end{array}$ & $\begin{array}{c}\text { Número de } \\
\text { Camadas }\end{array}$ & $\begin{array}{c}\text { Número de Golpes } \\
\text { por camada }\end{array}$ & $\begin{array}{c}\text { Volume do } \\
\text { cilindro }\left(\mathbf{c m}^{\mathbf{3}}\right)\end{array}$ \\
\hline Normal & 4,5 & 5 & 12 & 2000 \\
\hline Intermediária & 4,5 & 5 & 26 & 2000 \\
\hline Modificada & 4,5 & 5 & 55 & 2000 \\
\hline
\end{tabular}

Tabela 4 - Valores de energia do ensaio Proctor.

\begin{tabular}{l|c|c}
\hline \multicolumn{1}{c}{ Energia } & Energia por volume $\left(\mathbf{J} / \mathbf{c m}^{3}\right)$ & Energia por massa (J/g) \\
\hline Normal & 0,59 & 0,33 \\
\hline Intermediária & 1,30 & 0,68 \\
\hline Modificada & 2,78 & 1,39 \\
\hline
\end{tabular}

Os procedimentos adotados para a realização do ensaio de compactação no CGS, de uma maneira geral, foram semelhantes aos utilizados no ensaio de compactação Proctor. Os corpos de prova foram moldados com uma massa úmida de $1000 \mathrm{~g}$ em uma única camada, onde os dados iniciais de ensaio foram escolhidos com base nos ensaios de compactação Proctor. Também foram utilizados os três níveis de energias na tentativa de se fazer uma análise mais abrangente entre os dois métodos de compactação (Figura 3).
Os parâmetros de configuração do compactador giratório para esta pesquisa, tais como: tensão normal, ângulo de giro, frequência, números de giros foram escolhidos com base nas considerações apresentadas no trabalho de Dantas (2013). Neste foi feita uma correlação entre o número de giros e a energia empregada nos ensaios do CGS que podem ser checados na tabela 5 .

As curvas de compactação dos ensaios no CGS, assim como na compactação Proctor, foram 
definidas por meio dos valores de massa específica aparente seca e teor de umidade. A tabela 5 apresenta as energias empregadas nos ensaios de compactação no CGS por unidade de volume para os pontos ótimos das curvas de compactação. Estes valores são utilizados para efeito de comparação dos resultados de compactação Proctor e CGS, pois é necessário que sejam aplicadas as mesmas energias nos dois procedimentos de compactação. Portanto, foram calculadas as energias de acordo com os parâmetros de compactação utilizados (Tabela 5, número de giros, tensão normal, etc.). Após comparação dos resultados das tabelas 4 e 6, pode ser observado que as energias normal, intermediária e modificada para os três tipos de solo são semelhantes para os dois processos de compactação (Proctor e CGS).

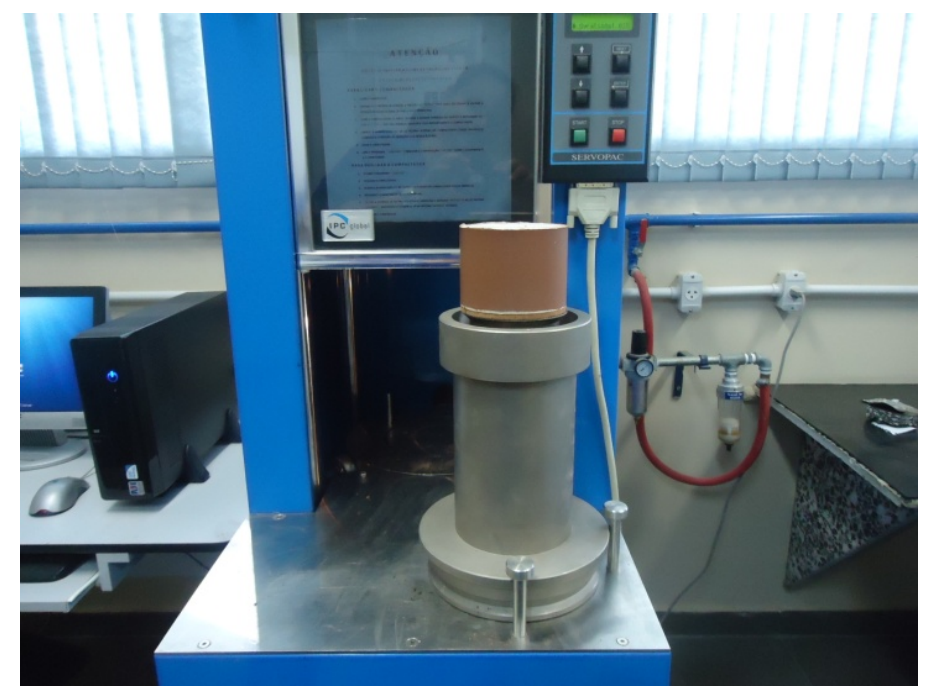

Figura 3 - Corpo de prova desmoldado após a compactação no CGS

Tabela 5 - Valores de energia do ensaio CGS (Dantas, 2013).

\begin{tabular}{l|c|c|c|c}
\hline \multicolumn{1}{c|}{ Energia } & $\begin{array}{c}\text { Tensão Normal } \\
\text { (KPa) }\end{array}$ & $\begin{array}{c}\text { Número de } \\
\text { giros }\end{array}$ & $\begin{array}{c}\text { Ângulo de } \\
\text { giro (graus) }\end{array}$ & $\begin{array}{c}\text { Frequência de } \\
\text { giros (rpm) }\end{array}$ \\
\hline Normal & 600 & 15 & 1,25 & 30 \\
\hline Intermediária & 600 & 31 & 1,25 & 30 \\
\hline Modificada & 600 & 65 & 1,25 & 30 \\
\hline
\end{tabular}

Tabela 6 - Valores da energia para os pontos ótimos da compactação no CGS.

\begin{tabular}{l|c|c|c}
\hline \multirow{2}{*}{ SOLO } & \multicolumn{3}{|c}{ ENERGIA DE COMPACTAÇÕO (J/g) } \\
\cline { 2 - 4 } & NORMAL & INTERMEDIÁRIA & MODIFICADA \\
\hline Arenoso & 0,29 & 0,62 & 1,26 \\
\hline Siltoso & 0,29 & 0,74 & 1,43 \\
\hline Argiloso & 0,34 & 0,69 & 1,34 \\
\hline
\end{tabular}

\section{Ensaio de resistência à tração por compressão diametral}

Para a realização do ensaio de resistência à tração por compressão diametral foram moldados três corpos de prova para cada solo e cada energia, todos com aproximadamente $100 \mathrm{~mm}$ de diâmetro e altura final média, de aproximadamente $60 \mathrm{~mm}$, medidas em três pontos distantes entre si por $120^{\circ}$ (graus).

$\mathrm{O}$ teor de umidade ótima utilizado na moldagem dos corpos de prova foi determinado a partir dos resultados dos parâmetros ótimos do ensaio de compactação. Após a moldagem, os corpos de prova ficaram expostos às condições atmosféricas por 48 horas, pois observou-se que não havendo esse tempo mínimo não era possível a realização do ensaio por não haver resistência do corpo de prova. Durante esse período de 48 horas ocorre uma desidratação do corpo de prova que propicia uma melhora na resistência.

\section{Ensaio de resistência à compressão simples}

Para a realização do ensaio de resistência à compressão simples foram moldados três corpos de prova para cada solo e cada energia, todos com aproximadamente $100 \mathrm{~mm}$ de diâmetro e altura 
final média, de aproximadamente $130 \mathrm{~mm}$, medida em três pontos distantes entre si por $120^{\circ}$. $\mathrm{O}$ teor de umidade utilizado na moldagem dos corpos de prova foi determinado a partir dos resultados dos parâmetros ótimos do ensaio de compactação. Após a moldagem, os corpos de prova ficaram expostos às condições atmosféricas por 24 horas.

\section{RESULTADOS E DISCUSSÕES}

Propriedades Físicas dos Solos

\section{Granulometria e Limites de Consistência}

As curvas granulométricas dos três solos estão apresentadas na Figura 4. Os resultados obtidos nos ensaios de limite de liquidez, limite de plasticidade e do cálculo do Índice de Plasticidade constam na tabela 7.

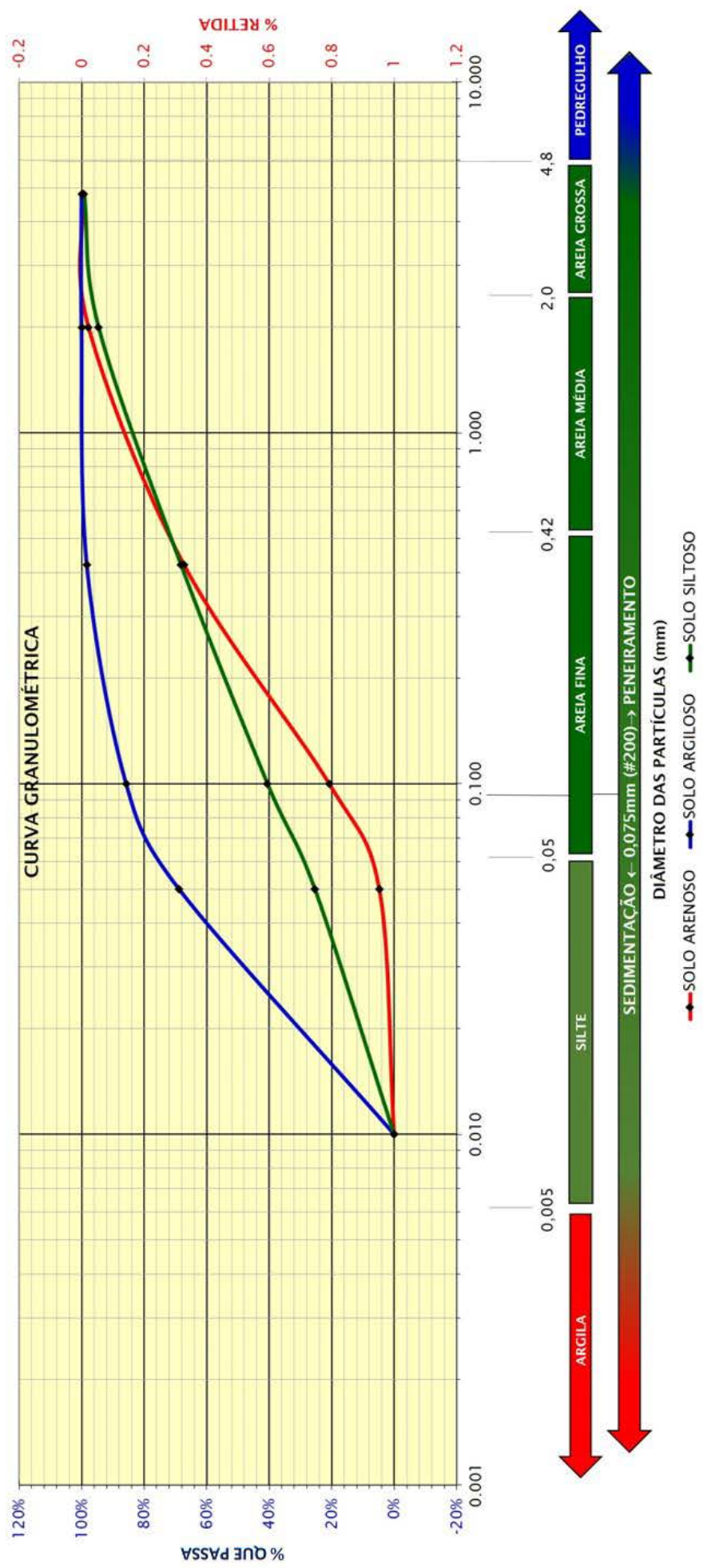

Figura 4 - Curva granulométrica dos solos. 
Tabela 7 - Limites de Consistência dos Solos.

\begin{tabular}{l|c|c|c}
\hline Tipo de solo & $\begin{array}{c}\text { Limite de } \\
\text { Liquidez (\%) }\end{array}$ & $\begin{array}{c}\text { Limite de } \\
\text { Plasticidade (\%) }\end{array}$ & $\begin{array}{c}\text { Índice de } \\
\text { Plasticidade (\%) }\end{array}$ \\
\hline Arenoso & Não Líquido & Não Plástico & Não Plástico \\
\hline Siltoso & 19 & 16 & 3 \\
\hline Argiloso & 39 & Não Plástico & 39 \\
\hline
\end{tabular}

Com os resultados da distribuição granulométrica das partículas e os limites de consistência, os solos foram classificados segundo a metodologia HRB (Highway Research Board), na qual se utilizou a norma AASHTO M-145-91. Portanto, os solos foram classIficados como: A - 3 (areia fina), A-2-4 (areia siltosa) e A-6 (solo argiloso). Para o SUCS (Sistema Unificado de Classificação de Solos), a norma empregada foi a ASTM D2487-11, e solos foram classificados como: SW (areia bem graduada), SM (areia siltosa mal graduada) e CL (argila inorgânica).

\section{Propriedades Mecânicas dos Solos Ensaios de Compactação}

As figuras 5, 6 e 7 apresentam as curvas de compactação para os três tipos de solo nas três energias: Normal, Intermediária e Modificada sendo (a) compactação Proctor e (b) compactação CGS.

Observou-se na compactação Proctor, quanto ao efeito da energia de compactação, que as massas específicas secas máximas aumentaram e as umidades ótimas diminuíram com o acréscimo de energia, o que confirma a tendência esperada.
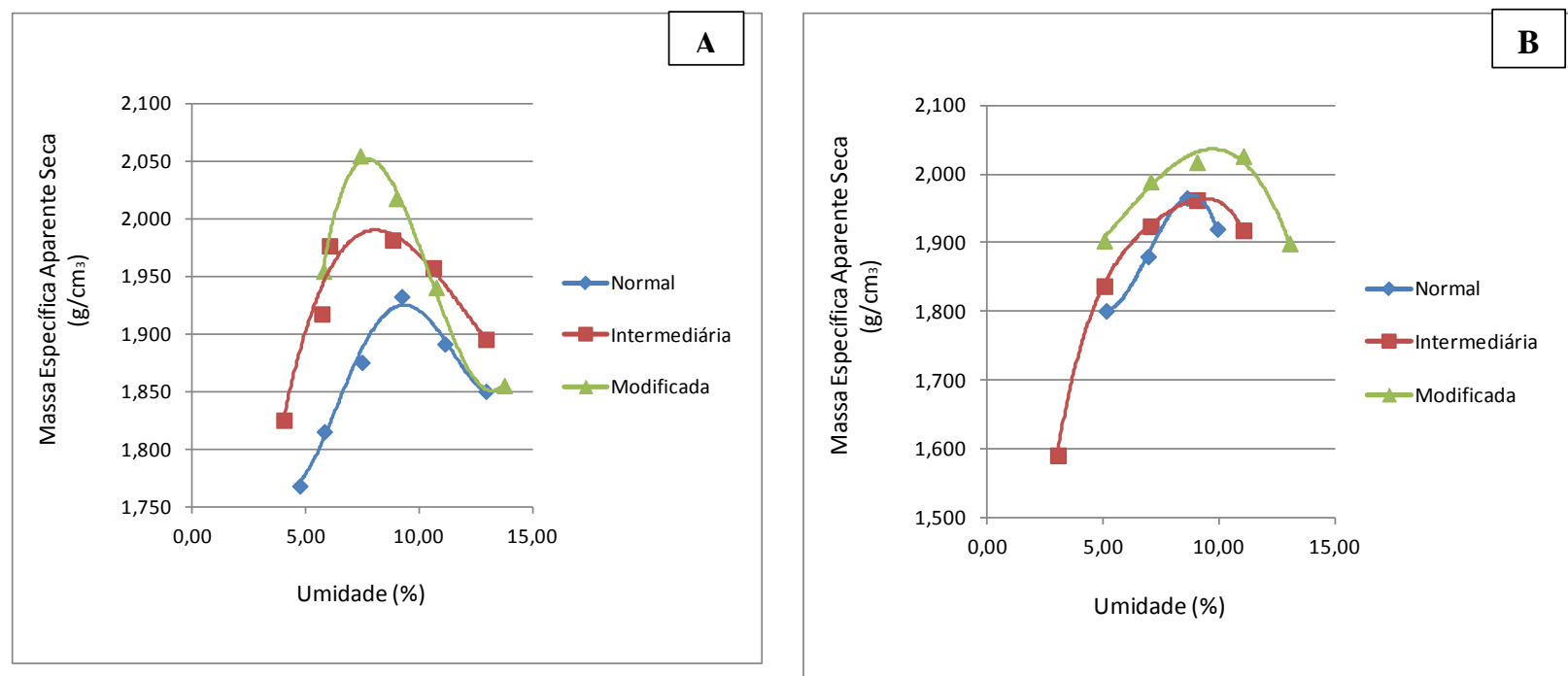

Figura 5 - Curvas de compactação do solo arenoso (A) Proctor e (B) CGS.
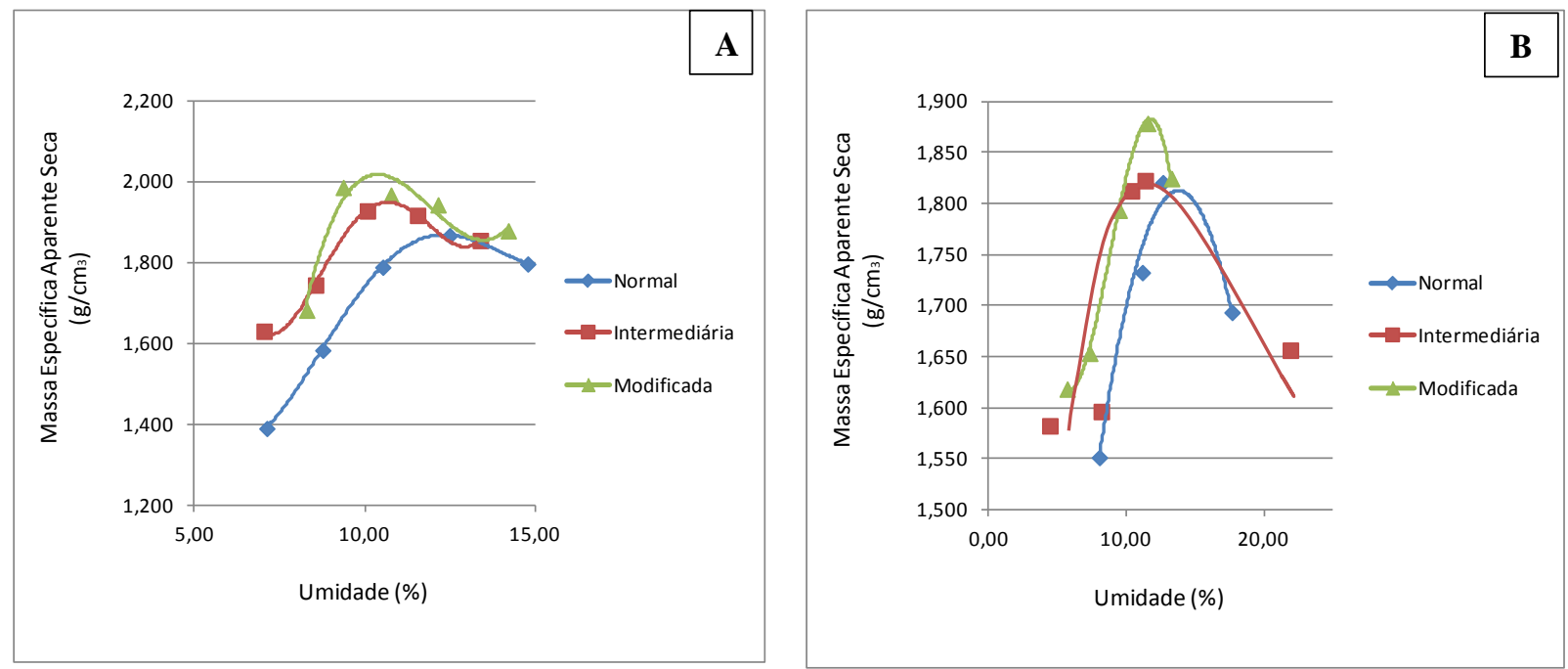

Figura 6 - Curvas de compactação do solo siltoso (A) Proctor e (B) CGS. 

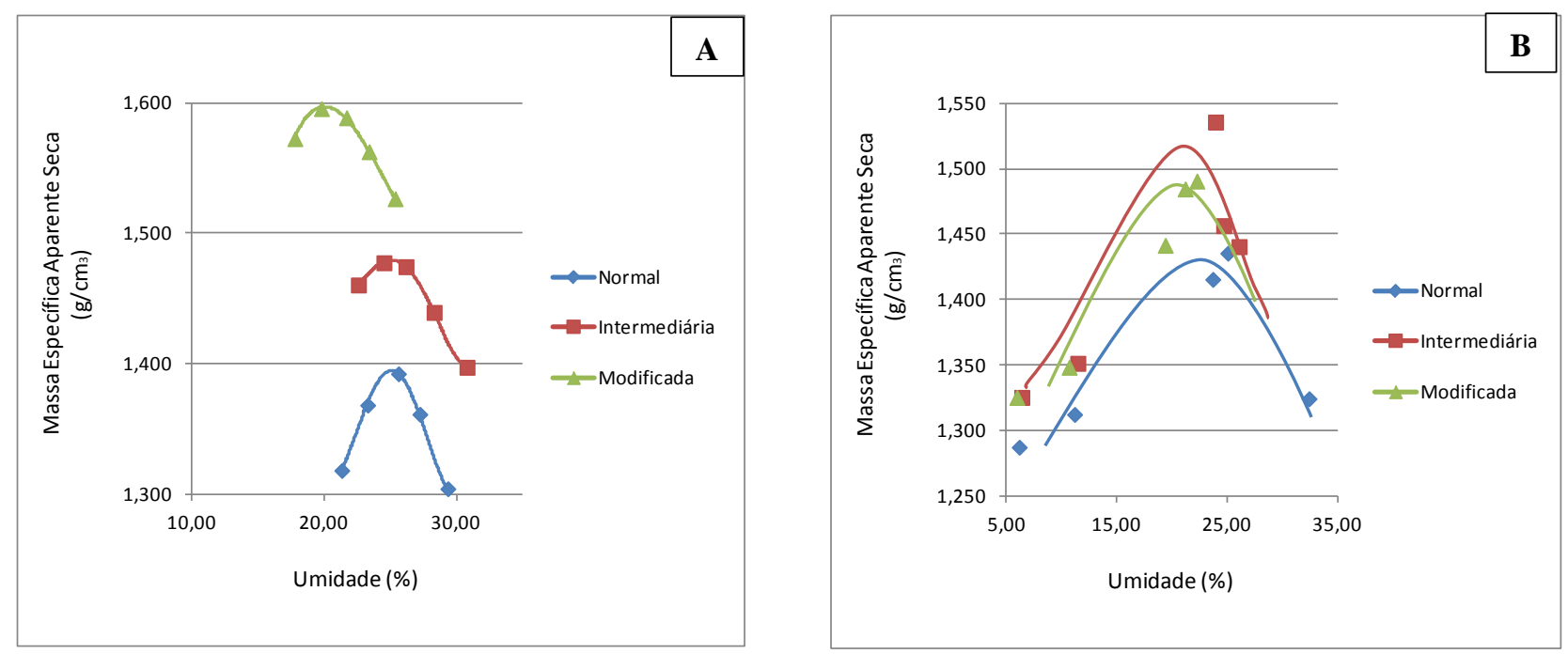

Figura 7 - Curvas de compactação do solo argiloso (A) Proctor e (B) CGS.

No entanto, foi observado que as massas específicas tiveram uma variação muito pequena em função do aumento da energia, essa observação foi relatada por Cernica (1995) que verificou que os acréscimos de massa específica raramente excedem $10 \%$, quando se compara os resultados da energia modificada com a energia normal. Observam-se resultados semelhantes de MEASmáx para a compactação Proctor e CGS. Dois pontos devem ser destacados. Primeiro, a compactação no ensaio Proctor é realizada em 5 camadas, já no CGS em camada única. A segunda peculiaridade refere-se a perda de umidade pela face inferior do molde durante o procedimento de compactação no CGS quando utilizado o solo arenoso, este fato influencia diretamente na determinação do teor de umidade após a compactação do corpo de prova.

A tabela 8 apresenta o resumo dos resultados de MEASmáx e wo (\%) obtidos a partir da compactação Proctor e CGS para os três tipos de solo estudados. Estes resultados podem ser comparados com o comportamento esperado para os parâmetros ótimos da compactação quando utilizam-se solos com granulometrias distintas. Pode-se notar que os resultados são satisfatórios, pois maiores valores de MEASmáx e menores valores de wo (\%) são obtidos com solos mais grossos, ou seja, MEASarenoso $>$ MEASsiltoso $>$ MEASargiloso e wargiloso $>$ wsiltoso $>$ warenoso.

\section{Ensaio de Resistência à Tração por Compressão Diametral}

A figura 8 apresenta o gráfico comparativo para os três tipos de solos nas três energias: Normal, Intermediária e Modificada.

Conforme pode ser observado ocorreu um aumento no valor do RTCD para os solos arenoso e argiloso quando realizado o processo de compactação CGS em relação ao processo de compactação Proctor, entretanto, tal fato não ocorreu para o solo siltoso. No caso do solo siltoso existe uma perda de RTCD de cerca de 20 a $30 \%$ quando realizada a compactação CGS.

Tabela 8 - Resumo dos ensaios de compactação.

\begin{tabular}{l|c|c|c|c|c}
\hline \multirow{2}{*}{ SOLO } & \multirow{2}{*}{ ENERGIA } & \multicolumn{2}{|c|}{ PROCTOR } & \multicolumn{2}{c}{ CGS } \\
\cline { 3 - 6 } & & $\boldsymbol{w}_{\boldsymbol{o}}(\%)$ & MEAS $_{\text {máx }}\left(\mathrm{g} / \mathrm{cm}^{3}\right)$ & $\boldsymbol{w}_{\boldsymbol{o}}(\%)$ & $\begin{array}{c}\mathrm{MEAS}_{\text {máx }} \\
\left(\mathrm{g} / \mathrm{cm}^{3}\right)\end{array}$ \\
\hline & Normal & 9,20 & 1,925 & 8,57 & 1,966 \\
\hline Arenoso & Intermediária & 8,78 & 1,982 & 9,00 & 1,963 \\
\hline & Modificada & 7,34 & 2,055 & 11,00 & 2,027 \\
\hline & Normal & 11,60 & 1,910 & 12,59 & 1,821 \\
\hline Siltoso & Intermediária & 10,50 & 1,940 & 11,31 & 1,823 \\
\hline & Modificada & 9,34 & 1,930 & 11,49 & 1,879 \\
\hline Argiloso & Normal & 25,16 & 1,395 & 24,96 & 1,436 \\
\hline & Intermediária & 25,20 & 1,479 & 23,85 & 1,536 \\
\hline
\end{tabular}




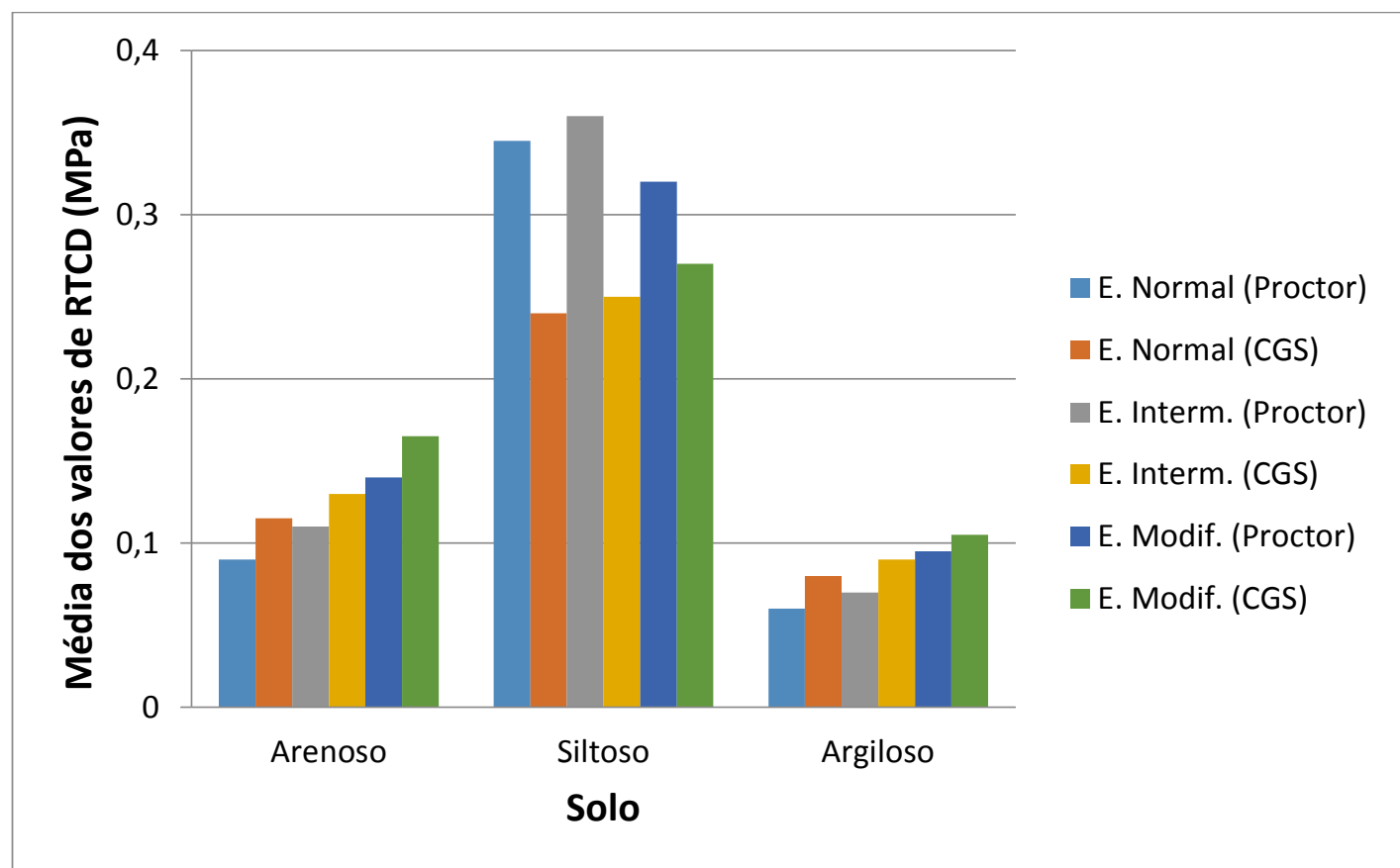

Figura 8 - Resultados de RTCD para os solos compactados no processo Proctor e CGS.

Este fato pode ser explicado em função da maior perda de umidade (umidade de moldagem $x$ umidade de compactação) ocorrida durante o processo de compactação Proctor quando comparado com o CGS. Quanto maior esta perda, maior será a influencia da sucção e consequentemente maior a resistência, principalmente em solos com granulometria mais fina. Fumió (2004) explica que este aumento de resistência, devido à sucção, deve-se à tensão negativa que se opõe à saída de água dos materiais e equivale a um acréscimo de pressão útil para movimentar um volume de água unitário do arcabouço sólido de um material.

\section{Ensaios de Resistência à Compressão Simples}

Na tabela 9 estão inseridos os resultados encontrados nos ensaios de RCS e a perda de umidade de moldagem ocorrida nos corpos de prova após 24 horas do término do ensaio para os dois tipos de moldagem: Proctor e CGS.

Tabela 9 - Resultados de RCS para os solos compactados no processo Proctor e CGS.

\begin{tabular}{c|c|c|c|c|c}
\hline \multirow{2}{*}{ SOLO } & \multirow{2}{*}{ ENERGIA } & \multicolumn{2}{|c|}{ PROCTOR } & \multicolumn{2}{c}{ CGS } \\
\cline { 3 - 6 } & & $\begin{array}{c}\text { w perdada (\%) } \\
\text { umidade de } \\
\text { moldagem }\end{array}$ & RCS (MPa) & $\begin{array}{c}\text { w perdada (\%) } \\
\text { umidade de } \\
\text { moldagem }\end{array}$ & RCS (MPa) \\
\hline & Normal & 1,79 & 0,64 & 2,13 & 0,24 \\
\hline Arenoso & Intermediária & 0,63 & 1,62 & 2,22 & 0,25 \\
\hline & Modificada & 0,73 & 1,96 & 2,93 & 0,47 \\
\hline & Normal & 3,54 & 0,40 & 1,50 & 2,53 \\
\hline Siltoso & Intermediária & 2,00 & 0,82 & 1,73 & 3,60 \\
\hline & Modificada & 2,62 & 2,16 & 2,42 & 4,93 \\
\hline \multirow{2}{*}{ Argiloso } & Normal & 2,61 & 0,32 & 4,59 & 0,36 \\
\hline & Intermediária & 2,36 & 0,34 & 4,37 & 0,48 \\
\hline
\end{tabular}

Conforme pode ser observado na tabela 8 ocorreu um aumento no valor do RCS para os solos siltoso e argiloso quando realizado o processo de compactação CGS em relação ao processo de compactação Proctor, entretanto, tal fato não ocorreu para o solo arenoso.
Dois pontos são importantes para tentar explicar os resultados obtidos para o ensaio de RCS no solo siltoso. O primeiro é perda da umidade de moldagem - relação entre a umidade quando na ruptura dos corpos de prova e da umidade aferida após o término do ensaio - 
e o segundo é a diferença de altura dos corpos de prova moldados no CGS (Figura 9).

Os CPs moldados no CGS apresentaram uma menor altura do que os moldados no Proctor, e consequentemente menor volume e maior massa especifica. Portanto, infere-se que os corpos de prova sejam mais densos, uma vez que apresentam menores índices de vazios, do que os moldados no Proctor, justificando o aumento da resistência à compressão simples.

A segunda hipótese seria pelo fato do solo siltoso apresentar uma menor perda de umidade de moldagem para o CGS do que no Proctor. Devido a isto, o esperado seria ocorrer uma maior ação da sucção devido à diminuição de umidade no Proctor e com isso um aumento da resistência no solo siltoso moldados nas condições supracitadas. Entretanto, isto não foi verificado uma vez que as amostras com menor perda de umidade apresentaram maior RCS, evidenciando, novamente, a eficácia da compactação CGS.

Os corpos de prova do solo argiloso apresentaram proporcionalidade entre a RCS e a perda de umidade. Observou-se que para o solo argiloso a perda de umidade de moldagem foi maior para o CGS em relação ao Proctor, e com isso a diferença dos resultados da RCS pode ser explicado por uma maior ação da sucção no CGS.

Esta influência da sucção na RCS era esperada em virtude deste ser um solo com granulometria fina e, portanto, mais susceptível a este comportamento.

\section{CONCLUSÕES}

Esta pesquisa apresenta um estudo de viabilidade do uso do compactador CGS na execução de ensaios de compactação de três tipos de solos (arenoso, siltoso e argiloso) em três níveis de energia (normal, intermediária e modificada).

De um modo geral, observou-se que a compactação giratória no CGS é um método viável de compactação de solo em laboratório, entretanto, para que o CGS seja usado rotineiramente na compactação de solos em laboratório algumas dificuldades necessitam ser superadas, como por exemplo, o custo do equipamento quando comparado ao custo de um equipamento de moldagem Proctor convencional.

Outra dificuldade que merece ser destacada é a necessidade da implementação de medidas que tenham como objetivo diminuir a percolação de água nas amostras de solos mais permeáveis durante o procedimento de compactação. A máquina do CGS foi projetada inicialmente para compactação de misturas asfálticas, mas com o uso da máquina para compactar amostras de solo um problema visível é a perda de água durante a compactação de solos úmidos. O esqueleto do solo é comprimido e a água e o ar são forçados a sair do espaço vazio. Dependendo do teor de umidade e da permeabilidade do solo, a água pode percolar pela face inferior do molde, modificando assim a umidade do corpo de prova após a compactação.

\section{REFERÊNCIAS}

AMERICAN ASSOCIATION OF STATE HIGHWAY AND TRASPORTATION OFFICIALS. (2004) AASHTO M-14591. Standard Specification for Classification of Soils and Soil-Aggregate Mixtures for Highway Construction Purpose. Washington, EUA.

AMERICAN SOCIETY FOR TESTING AND MATERIALS. (2011). ASTM D2487-11. Standard Practice for Classification of Soils for Engineering Purposes (Unified Soil Classification System). Pensilvânia, EUA.

ASSOCIAÇÃO BRASILEIRA DE NORMAS TÉCNICAS (1984). NBR 6459. Solo-Determinação do limite de liquidez. Rio de Janeiro.

ASSOCIAÇÃO BRASILEIRA DE NORMAS TÉCNICAS (1984). NBR 7180. Solo-Determinação do limite de plasticidade. Rio de Janeiro.

ASSOCIAÇÃO BRASILEIRA DE NORMAS TÉCNICAS (1984). NBR 7181. Solo-Análise granulométrica. Rio de Janeiro.

ASSOCIAÇÃO BRASILEIRA DE NORMAS TÉCNICAS (2012). NBR 12025. Solo-cimento-Ensaio de compressão simples de corpos de prova cilíndricos-Método de ensaio.
Rio de Janeiro.

BROWNE, M. Feasibility of Using a Gyratory Compactor to Determine Compaction Characteristics of Soil. Montana, 2006. 142p. Dissertação (Mestrado), Departamento de Engenharia Civil-Universidade do Estado de Montana.

CERNICA, J.N. Geotechnical Engineering: Soil Mechanics. New York: John Wiley \& Sons, 454p., 1995.

DANTAS, G.H.S. Estudo do emprego do compactador giratório Superpave na compactação de um solo argiloso. São Carlos, 2013. 125p. Dissertação (Mestrado), Escola de Engenharia de São Carlos - Universidade de São Paulo.

DEPARTAMENTO NACIONAL DE ESTRADAS E RODAGEM. DNER-ME 162/94 (1994). Solos - ensaio de compactação utilizando amostras trabalhadas. Rio de Janeiro.

DEPARTAMENTO NACIONAL DE ESTRADAS E RODAGEM. DNER-ME 136/2010 (2010). Pavimentação asfáltica-Misturas asfálticas-Determinação da resistência à tração por compressão diametral-Método de ensaio. Rio de Janeiro.

FUMIÓ, B.L.C. Solos não saturados e drenagem de camadas 
próximas da superfície de vias e pavimentos. São Carlos, 2004. 113p. Tese (Doutorado), Escola de Engenharia de São Carlos - Universidade de São Paulo.

Holtz, R.D. \& Kovacs, W.D. An introduction to Geotechnical Engineering. New Jersey: Prentice-Hall Inc. Englewood Cliffs, 34p., 1981.

MARQUES, G.L.O. Utilização do Módulo de Resiliência como Critério de Dosagem de Mistura Asfáltica; Efeito da Compactação por Impacto e Giratória. Rio de Janeiro, 2004. 490p. Tese (Doutorado), Universidade Federal do Rio de Janeiro.
MOKWA, R.; Cuelho, E.; Browne, M. Laboratory Testing of Soil Using the Superpave Gyratory Compactor. Transportation Research Board, v. 1, n. 1, p. 14-17, 2008. PING, W.V., LEONARD, M.; YANG, Z. Laboratory Simulation of Field Compaction Characteristics (Phase I). Departamento de Engenharia Civil e Ambiental, Universidade do Estado da Florida. Tallahassee, Florida. 2003.

Submetido em 24 de novembro de 2017 Aceito em 25 de janeiro de 2018 